\title{
Imagen mental y su relación con los aspectos cognitivos y personalidad
}

\author{
Mental imagery and the relation with cognitive and personality aspects
}

\author{
Mario Lado, Alfredo Campos \\ Universidade de Santiago de Compostela
}

\begin{abstract}
Resumen
El objeto de este estudio era investigar la relación entre la habilidad para crear y rotar imágenes mentales y aspectos cognitivos como la memoria, la habilidad para el cálculo aritmético o habilidades mentales generales; asimismo, se investiga la relación entre la creación de imágenes mentales y las características de personalidad. Los resultados obtenidos indican que las personas con mayor habilidad para crear imágenes espaciales presentan mejores resultados en las habilidades cognitivas medidas en este estudio. Los resultados también indican que la habilidad para crear imágenes espaciales presenta correlaciones significativas con los factores Energía y Tesón.
\end{abstract}

Palabras clave: imagen mental, cognición, personalidad

\begin{abstract}
The purpose of this study was to investigate the relationship between the ability rotate spatial mental images and cognitive aspects such as memory, the ability for arithmetic and general mental abilities; also, the relationship between the ability to rotate spatial mental images and personality characteristics were investigated.. The results indicate that people with higher ability to create and rotate mental spatial imagery have better results on cognitive abilities measured in this study; also, the results indicate that the ability to rotate spatial mental imagery show significant correlations with two of the five personality factors: Energy and Conscientiousness.
\end{abstract}

Keywords mental imagery, cognition, personality

\section{Introducción}

La habilidad para crear imágenes mentales ha sido objeto de estudio en las últimas décadas, principalmente con el fin de diseñar instrumentos para su adecuada medida, así como para estudiar la influencia de esta habilidad en otras características de los individuos. A lo largo de este tiempo se han llevado a cabo estudios con el fin de diseñar instrumentos de medida (Blajenkova, Kozhevnikov \& Motes, 2006; Burton \& Fogarty, 2003; Campos, 2009, 2012), así como otros estudios para comprobar las propiedades psicométricas (Burton \& Fogarty, 2003; Campos \& Pérez-Fabello, 2011a, 2011b). Además, se han llevado a cabo numerosos estudios analizando la influencia de la habilidad para crear imágenes espaciales y otras características, por ejemplo, creatividad de imágenes espaciales y rendimiento académico (Campos y González, 1993, 1994b, 1994c, 1994d); creatividad e inteligencia y desempeño (Edwards \& Tyler, 1965; Gervilla, 1987); imágenes mentales y procesos verbales (Paivio, 1971); e imágenes mentales y pensamiento creativo (Shaw \& DeMers, 1986), etc.

Por otra parte, existen bastantes estudios que analizan la relación entre la habilidad para crear imágenes espaciales y la habilidad mental general, o habilidades cognitivas específicas (Gaddes, McKenzie \& Barnsley, 1968; Richardson, 1978), así como estudios que relacionen la habilidad de crear imágenes mentales y las características de personalidad de los individuos (Gralton, Hayes, \& Richardson, 1979; Hasegawa, 1990; McDougall \& Pfeifer, 2012). El estudio de Gaddes et al. (1968) no aportaba correlaciones significativas entre la habilidad para crear imágenes espaciales e inteligencia; de la misma manera, el estudio de Richardson (1978) mostró que no existía correlación entre la habilidad de crear imágenes espaciales y la memoria. Por otra parte, el estudio de Gralton et al. (1979) mostró datos que indicaban que las personas con baja puntuación en Extroversión (denominada también "Energía” por otros autores) experimentarían imágenes mentales con más viveza que las personas con alta puntuación en extroversión; sin embargo, el estudio de McDougall \& Pfeifer (2012) aportó datos en el sentido opuesto, al igual que el estudio de Hasegawa (1990).

Este estudio pretende aportar datos a partir de dos análisis: por una parte, datos acerca de la interacción entre la habilidad de crear imágenes espaciales y otros tipos de habilidades cognitivas: habilidad para memorizar caras, habilidad para memorizar imágenes cotidianas, habilidad para solucionar problemas de cálculo aritmético, y la habilidad mental general como una medida de un constructo formado por diversas habilidades cognitivas; y, además, este estudio pretende aportar datos acerca de la interacción de la habilidad de creación de imágenes mentales y las características de personalidad de los individuos, medidas a través de las puntuaciones en cinco factores de personalidad.

\section{Muestra}

Método

La muestra estaba compuesta por 172 alumnos que asistían a diversos cursos de Grado y Máster de la Universidad de Santiago de Compostela. El rango de edad oscilaba entre los 18 y los 51 años $(M=22,04 ; S D=$ 4.97); por sexos, 76 varones y 96 mujeres. Los datos fueron recogidos a lo largo de dos cursos académicos consecutivos, 2011-12 y 2012-13.

Instrumentos utilizados.

Se utilizaron los siguientes instrumentos de evaluación: Medida de la Aptitud para Rotar Imágenes 
Mentales (MARMI; Campos, 2012), Medida de la Aptitud para Formar Imágenes Mentales Espaciales (MASMI; Campos, 2009; 2013), Cuestionario de Personalidad Big Five (BFQ; Caprara, Barbaranelli, y Borgogni, 1995), Prueba de Habilidad de Cálculo (CSG-PHC; Lado, 2008a), Prueba de Memoria de Caras (CSG-PMC; Lado 2008b), Prueba de Memoria Visual (CSG-PMV; Lado, 2008c) y Prueba de Habilidad Mental General (CSG-HMG 1.60; Lado, 2008d).

El MARMI (Campos, 2012) consiste en una prueba diseñada para medir la habilidad para rotar imágenes mentales utilizando un cubo desplegado que los individuos tienen que componer mentalmente y rotarlo sobre dos ejes antes de responder a 23 preguntas acerca del cubo. El rango de las puntuaciones de esta prueba abarca desde -46 a +46 puntos y presenta un alpha de Cronbach de 0.90 .

El MASMI (Campos, 2009; 2013) consiste en una prueba en la que, a partir de la imagen de un cubo desplegado, los individuos tienen que volver a montar mentalmente antes de responder a 23 preguntas relacionadas con el cubo. El rango de las puntuaciones abarca desde -46 a +46 puntos y presenta un alpha de Cronbach de 0.93 .

El BFQ (Caprara et al., 1995) es un cuestionario de personalidad, que incluye 132 ítems, basado en el modelo de los cinco grandes factores de personalidad y que en este cuestionario son denominados Energía, Afabilidad, Tesón, Estabilidad Emocional y Apertura Mental y cuyos coeficientes alpha son 0.75 para el factor de Energía, 0.73 para Afabilidad, 0.79 para Tesón, 0.87 para Estabilidad Emocional y 0.76 para Apertura mental.

La prueba CSG-PHC (Lado, 2008a) consiste en completar el mayor número posible de ejercicios de cálculo matemático; incluye 90 ejercicios presentados con una secuencia de una suma, una resta, una multiplicación y una división.

La prueba CSG-PMC (Lado, 2008b) consiste en una prueba en la que se les presenta a los individuos un conjunto de caras con una serie de datos asociados; posteriormente, los individuos contestan en un cuestionario a 8 preguntas, con cuatro opciones de respuesta y solamente una correcta, relacionadas con la identificación de caras.

La prueba CSG-PMV (Lado, 2008c) consiste en una prueba de en la que se les presenta a los individuos un gráfico de una supuesta zona urbana de una ciudad y que incluye elementos habituales de ese contexto; éstos, posteriormente, tienen que visualizar ese gráfico y contestar a un cuestionario de 20 preguntas que contienen 4 opciones de respuesta y solamente una correcta.

La prueba CSG-HMG (Lado, 2008d) mide un conjunto de habilidades cognitivas e incluye un total de 60 preguntas, con series lógicas de números y letras, silogismos numéricos, sinónimos y antónimos, giros y rotaciones de figuras, completar imágenes tridimensionales, etc.

\section{Procedimiento}

En el momento de obtener los datos los alumnos realizaban unas prácticas pertenecientes a sus respectivos programas de sesiones interactivas, todas ellas relacionadas con la evaluación en recursos humanos. Se les administraron diversas pruebas con el fin de conocer diversos instrumentos de evaluación así como obtener, posteriormente, determinados estadísticos descriptivos e interpretar los resultados.

La medida en imagen mental se presenta dicotomizada tomando como referencia la media aritmética en las puntuaciones del MARMI y MASMI; en ambas pruebas, los individuos con una puntuación inferior a la media del grupo fueron considerados como bajos en imagen mental, mientras que los que obtuvieron puntuaciones por encima de la media fueron considerados altos en imagen mental. En las demás pruebas, la medida se presenta con las puntuaciones directas obtenidas por los individuos en cada una de ellas.

\section{Resultados}

Se ha llevado a cabo un Análisis Multivariante de la Varianza (MANOVA) de 2 (dos niveles de habilidad para rotar imágenes) x 2 (dos niveles de habilidad para formar imágenes). Las variables dependientes se expresaron a través de las puntuaciones directas en las pruebas de habilidad CSG-PHC, CSG-PMC, CSG-PMV y CSG-HMG 1.60. En las tablas 1 y 2 se muestran las medias y las desviaciones típicas de las puntuaciones.

Tabla 1.

Medias y desviaciones típicas en las pruebas de Marmi.

\begin{tabular}{lllcr}
\hline & \multicolumn{2}{c}{$\begin{array}{c}\text { MARMI } \\
\text { (Bajos) }\end{array}$} & \multicolumn{2}{c}{$\begin{array}{c}\text { MARMI } \\
\text { (Altos) }\end{array}$} \\
\cline { 2 - 5 } Medidas & $M$ & $S D$ & $M$ & $S D$ \\
\hline CSG-PHC & 16,26 & 8,26 & 4,83 & 11,6 \\
CSG-PMC & 7,09 & 1,10 & 6,83 & 1,00 \\
CSG-PMV & 8,69 & 3,45 & 1,79 & 3,11 \\
CSG-HMG & 30,67 & 9,56 & 2,56 & 9,18 \\
\hline
\end{tabular}

Tabla 2.

Medias y desviaciones típicas en las pruebas de Masmi.

\begin{tabular}{lllrl}
\hline & \multicolumn{2}{c}{$\begin{array}{c}\text { MASMI } \\
\text { (Bajos) }\end{array}$} & \multicolumn{2}{c}{$\begin{array}{c}\text { MASMI } \\
\text { (Altos) }\end{array}$} \\
\cline { 2 - 5 } Medidas & $M$ & \multicolumn{1}{c}{$S D$} & \multicolumn{1}{c}{$M$} & \multicolumn{1}{c}{$S D$} \\
\hline CSG-PHC & 15,12 & 6,88 & 25,21 & 11,6 \\
CSG-PMC & 6,92 & 1,13 & 7,12 & 0,98 \\
CSG-PMV & 8,73 & 3,51 & 11,26 & 3,32 \\
CSG-HMG & 28,24 & 8,07 & 44,29 & 6,89 \\
\hline
\end{tabular}

El criterio de Wilks indicó que había diferencias significativas entre altos y bajos en rotación y creación de imágenes con las medidas en las cuatro variables de habilidades: habilidad de cálculo, memoria de caras, memoria visual y habilidades mentales generales. Los resultados fueron (Lambda de Wilks $=.80, F(4,76)=$ 4.892, $p<.001$ ) con respecto al MARMI y (Lambda de Wilks $=.59, F(4,76)=13.206, p<.001)$ en el caso del MASMI. Por otra parte, la interacción entre el MARMI y el MASMI no fue significativa (Lambda de Wilks = .95, $F(4,76)=0.99, p=.42$ ).

Se efectuaron los análisis univariados para ver la influencia del MARMI y MASMI en las variables de 
habilidades y encontramos que el MARMI no influyó significativamente en la habilidad para memorizar caras, $F(1,79)=2.412, p=.12$; sin embargo, influyó significativamente en la habilidad para memorizar imágenes $F(1,79)=8.110, p=.01$; por tanto, los individuos con alta capacidad para rotar imágenes mentales espaciales tuvieron mayor puntuación en la habilidad para memorizar imágenes $(M=11.79, S D=$ 3.1) que las personas con baja capacidad para rotar imágenes espaciales $(M=8.69, S D=3.45)$.

En cuanto a influencia del MARMI en la habilidad mental general, los resultados indican que fue significativa $F(1,79)=7.88, p=.01$; los individuos con alta capacidad para rotar imágenes mentales espaciales tuvieron mayor puntuación en la habilidad mental $(M=$ 42.55, $S D=9.18$ ) que las personas con baja capacidad para rotar imágenes espaciales $(M=30.67, S D=9.55)$.

La influencia del MARMI también resultó significativa en la habilidad de cálculo, $F(1,79)=3.772$, $p=.05$; los individuos con alta capacidad para rotar imágenes mentales espaciales tuvieron mayor puntuación en la habilidad para el cálculo $(M=24.83, S D$ = 11.59) que las personas con baja capacidad para rotar imágenes espaciales $(M=16.26, S D=8.26)$.

En el caso del MASMI, no se ha encontrado una influencia significativa en la habilidad para memorizar caras, $F(1,79)=1.273, p=.26$, ni en la habilidad para memorizar imágenes, $F(1,79)=2.227, p=.14$; $\sin$ embargo, esa influencia sí apareció significativa en la habilidad mental general, $F(1,79)=48.154, p=.001$; los individuos con alta capacidad para formar imágenes mentales espaciales tuvieron mayor puntuación en la habilidad para el cálculo $(M=25.21, S D=11.61)$ que las personas con baja capacidad para formar imágenes espaciales $(M=15.12, S D=6.88)$.

Por último, la influencia del MASMI también apareció significativa en la habilidad para el cálculo, $F(1,79)=$ 13.017, $p=.001$; los individuos con alta capacidad para formar imágenes mentales espaciales tuvieron mayor puntuación en la habilidad mental general $(M=44.29$, $S D=6.89)$ que las personas con baja capacidad para formar imágenes espaciales $(M=28.24, S D=8.07)$.

Posteriormente se llevó a cabo otro Análisis Multivariante de la Varianza (MANOVA) de 2 (dos niveles de habilidad para rotar imágenes) x 2 (dos niveles de habilidad para formar imágenes espaciales). Las variables dependientes se expresaron a través de las puntuaciones directas en los factores de personalidad: extroversión (también denominado energía), afabilidad, tesón, estabilidad emocional y apertura mental.

En las Tablas 3 y 4 se muestran las medias y las desviaciones típicas de las puntuaciones de los participantes en los cuestionarios de Personalidad y con puntuaciones altas y bajas en Marmi; en la Tabla 4 se muestran las medias y desviaciones típicas de las puntuaciones de los participantes en personalidad con puntaciones altas y bajas en Masmi.

Los resultados indican que, según el criterio de Wilks, no había diferencias significativas entre altos y bajos en rotación y creación de imágenes con las medidas de los cinco factores de personalidad; los resultados fueron (Lamba de Wilks $=.96, F(5,134)=1.267, p$ $=.28$ ) para el MARMI y, en el caso del MASMI (Lamba de Wilks $=.93, F(5,134)=2.085, p=.07)$. Con estos datos se puede deducir que, en el caso del MARMI, las diferencias no resultaron significativas, mientras que en el caso del MASMI resultaron marginalmente significativas.

Tabla 3.

Medias y desviaciones típicas en Marmi.

\begin{tabular}{lcccr} 
& \multicolumn{2}{c}{ MARMI (Bajos) } & \multicolumn{2}{c}{ MARMI (Altos) } \\
\hline \multicolumn{1}{c}{ Medidas } & $M$ & $S D$ & $M$ & \multicolumn{1}{c}{$S D$} \\
\hline BFQ-EX & 78,88 & 12,45 & 75,46 & 12,04 \\
BFQ-AF & 84,09 & 9,97 & 83,21 & 8,4 \\
BFQ-T & 84,81 & 11,22 & 81,66 & 10,79 \\
BFQ-EE & 69,69 & 14,91 & 75,56 & 14,55 \\
BFQ-AM & 82,53 & 10,96 & 82,64 & 12,56 \\
\hline
\end{tabular}

Tabla 4.

Medias y desviaciones típicas en Masmi.

\begin{tabular}{lrrrr} 
& & \multicolumn{3}{c}{ MASMI (Altos) } \\
\hline \multicolumn{1}{c}{ Medidas } & \multicolumn{1}{c}{$M$} & \multicolumn{1}{c}{$S D$} & \multicolumn{1}{c}{$M$} & \multicolumn{1}{c}{$S D$} \\
\hline BFQ-EX & 77,35 & 11,98 & 77,48 & 12,94 \\
BFQ-AF & 84,38 & 9,02 & 82,8 & 9,69 \\
BFQ-T & 85,45 & 10,56 & 80,73 & 11,34 \\
BFQ-EE & 69,82 & 13,83 & 75,48 & 15,99 \\
BFQ-AM & 82,34 & 11,73 & 82,9 & 11,59 \\
\hline
\end{tabular}

Efectuamos los análisis univariados sólo para ver la influencia del MASMI en los factores de personalidad, y encontramos que el MASMI no influyó significativamente en BFQ-EX, $F(1,138)=1.106, p=$ .29 , ni en BFQ-AF, $F(1,138)=.701, p=.40)$, ni en BFQ-EE, $F(1,138)=1.389, p=.24)$, ni en BFQ-AM, $F(1,138)=.066, p=.79)$. Sin embargo, resultó significativa la diferencia en BFQ-TE entre los altos y bajos en el MASMI, $F(1,138)=3.755, p=.05)$. Los individuos con baja capacidad para formar imágenes mentales espaciales tuvieron mayor puntuación en el factor de Tesón $(M=84.81 ; S D=11.22)$ que las personas con alta capacidad para formar imágenes espaciales $(M=$ 81.66; $S D=10.79$ ). La interacción entre el MARMI y el MASMI no influyó en las puntuaciones de personalidad medidas por el BFQ, Lambda de Wilks = .94, $F(5,134)=$ 1.632, $p=.16$.

\section{Discusión}

En este estudio los datos indicaron que tanto las puntuaciones de los participantes en el MARMI, como en el MASMI influían significativamente en las puntuaciones de esos participantes en las pruebas de habilidad mental general y habilidad para el cálculo 
matemático. No aparecieron relaciones significativas entre el MARMI y el MASMI con las puntuaciones de los participantes en las pruebas de memoria (caras e imágenes visuales), excepto la relación entre MARMI y habilidad para memorizar imágenes visuales.

No aparecieron relaciones significativas entre las puntuaciones de los participantes en el MARMI y en el MASMI y las puntuaciones en los cinco factores de personalidad, a excepción de un solo valor, la relación entre las puntuaciones de los participantes en el MASMI y las puntuaciones en el factor de Tesón.

Los resultados, en general, parecen ir en la línea de los estudios antecedentes, de manera de que parece haber relaciones significativas entre las imágenes espaciales y las puntuaciones en memoria, pero solamente en algunos factores (p.e., Owens \& Richardson, 1979). Sin embargo, y a diferencia de estudios anteriores, la relación entre la creación de imágenes espaciales y las puntuaciones en la inteligencia sí que fueron significativas cuando ésta fue medida a través de un cuestionario de habilidad mental general, y la habilidad de cálculo matemático. Parece no haber relaciones significativas entre la creatividad de imágenes espaciales y la personalidad (p.e., McDougall \& Pfeifer, 2012).

Por último, sería conveniente confirmar los datos con una muestra más amplia y ampliar la investigación a otro tipo de habilidades cognitivas específicas, así como a los diferentes intereses vocacionales $\mathrm{y} / \mathrm{o}$ preferencias laborales de los participantes.

\section{Referencias}

Blajenkova, O., Kozhevnikov, M., \& Motes, M.A. (2006). Object-spatial imagery: A new self-report imagery questionnaire. Applied Cognitive Psychology, 20, 239-263. http://dx.doi.org/10.1002/acp.1182

Burton, L. J., \& Fogarty, G. J. (2003). The factor structure of visual imagery and spatial abilities. Intelligence, 31, 289-318.

Campos, A. (2009). Spatial imagery: A new measure of the visualization factor. Imagination, Cognition and Personality, 29, 31-39.

Campos, A. (2012). Measure of the ability to rotate mental images. Psicothema, 24, 431-434.

Campos, A. (2013). Reliability and percentiles of a measure of spatial imagery. Imagination, Cognition and Personality, 32, 427-431.

Campos, A., y González, M.A. (1993). Creatividad y rendimiento académico en estudiantes de Bellas Artes, Ciencias y Letras. Adaxe, 9, 19-28.

Campos, A., y González, M.A. (1994b). Los factores de imagen como determinantes del rendimiento académico en estudiantes de Bellas Artes. Revista Galega de Psicopedagoxía, 8-9, 201-208.

Campos, A., y González, M.A. (1994c). Importancia de la imagen y la creatividad en el rendimiento académico de estudiantes de bachillerato. Adaxe, 10, 21-30.

Campos, A., y González, M.A. (1994d). ¿Es la creatividad un factor determinante en los estudios de Bellas Artes? Revista Galega de Psicopedagoxía, 8-9, 209-217.

Campos, A., \& Pérez-Fabello, M.J. (2011a). Factor structure of the Spanish version of the object-Spatial
Imagery and Verbal Questionnaire. Psychological Reports, 108, 470-476.

Campos, A., \& Pérez-Fabello, M.J. (2011b). Some psychometric properties of the Spanish version of the clarity of auditory imagery scale. Psychological Reports, 109, 139-146.

Caprara, G.V., Barbaranelli, C. y Borgogni, L. (1995). BFQ: cuestionario" Big Five", versión española de J. Bermúdez. Madrid: TEA Ediciones.

Edwards, M.P., \& Tyler, L. (1965). Intelligence, creativity, and achievement in a non selective public junior high school. Journal of Educational Psychology, 56, 96-99.

Gaddes, W. H., McKenzie, A., \& Barnsley, R. (1968). Psychometric intelligence and spatial imagery in two Northwest Indian and two white groups of children. The Journal of Social Psychology, 75, 35-42.

Gervilla, A. (1987). Creatividad, inteligencia y rendimiento. Málaga: Universidad de Málaga.

Gralton, M.A.; Hayes, Y.A.; Richardson, J.T. (1979). Introversion-extraversion and mental imagery. Journal of Mental Imagery, 3, 1-10.

Hasegawa, K. (1990). Relationship between vividness of mental imagery and personality traits. Japanese Journal of Educational Psychology, 38, 306-311.

Holland, J.L. (1978). Investigación Autodirigida (Forma E). Florida, USA: PAR, Psychological Assessment Resources, Inc.

Lado, M. (2008a). CSG-PHC, Prueba de Habilidad de Cálculo. Universidad de Santiago de Compostela: Departamento de Psicología Social, Básica y Metodología.

Lado, M. (2008b). CSG-PMC, Prueba de Memoria Visual (versión C). Universidad de Santiago de Compostela: Departamento de Psicología Social, Básica y Metodología.

Lado, M. (2008c). CSG-PMV, Prueba de Memoria Visual (versión $M$ ). Universidad de Santiago de Compostela: Departamento de Psicología Social, Básica y Metodología.

Lado, M. (2008d). CSG-HMG 1.60, Prueba de Habilidad Mental General (Versión 1.60). Universidad de Santiago de Compostela: Departamento de Psicología Social, Básica y Metodología.

McDougall, S., \& Pfeifer, G. (2012). Personality differences in mental imagery and the effects on verbal memory. British Journal of Psychology, 103, 556-573.

Owens, A.C., \& Richardson, J.T.E. (1979). Mental imagery and pictorial memory. British Journal of Psychology, 70, 497-505.

Paivio, A. (1971). Imagery and verbal processes. New York: Holt, Rinehart and Winston.

Richardson, J.T. (1978). Mental imagery and memory: Coding ability or coding preference? Journal of Mental Imagery, 2, 101-116.

Shaw, G.A., \& DeMers, S.T. (1986). The relationship of imagery to originality, flexibility and fluency in creative thinking. Journal of Mental Imagery, 10, 65-74. 